\title{
The Impact of the Quality Assurance Unit on Quality Improvement in Zimbabwe Open University
}

\author{
Trust Nyenya \\ Regional Quality Assurance Coordinator \\ Zimbabwe Open University \\ Marondera, Zimbabwe \\ nyenyat@gmail.com
}

\author{
Benson Gabi \\ Quality Assurance Director \\ Zimbabwe Open University \\ Harare, Zimbabwe \\ bgabizou@ac.zw
}

\begin{abstract}
This qualitative inquiry explored the impact of the quality assurance unit using ZOU as a case study. The study generated data from participants at their work places, natural setting with the researchers as a key instrument in data collection whereby they conducted interviews. The inquiry focused on participants' perspectives and their subjective views of the impact of the quality assurance unit at ZOU. In addition to interviews, document analysis (media reports and internal documents) were conducted to gather evidence on the activities of the quality assurance unit. The research sought to identify the impact of the quality assurance unit in ZOU; therefore, the population for the study was the ZOU staff full time staff compliment of about 850, a part time staff compliment of about 1100 and a student body of about 11000 and major stakeholders. The manager quality assurance, 4 of the 10 regional directors, 4 of the 10 regional quality assurance coordinators, 4 of the 10 student representative council members, 12 of the 200 full time academics in 6 Faculties of ZOU were interviewed. This study has established that the Quality Assurance Unit in ZOU has positively impacted on teaching and learning, research and managerial practice resulting in the institution receiving three international awards between 2012 and 2015. Customer satisfaction improved over the period from 30.4\% in 2011 to $77.3 \%$ in 2013. University ranking improved from 11 in 2011 to 5 in 2014. Academics research output has increased from 242 in 2013 to 282 in 2014. In view of the several achievements made by the Quality Assurance Unit in $\mathrm{ZOU}$ the study strongly recommended that the unit continues to strive for excellence. Continued managerial support through resource allocation to address non-conformities is vital.
\end{abstract}

Keywords: Quality assurance, quality improvement, impact

\section{BACKGROUND TO THE STUDY}

Quality assurance is no longer an option in open and distance learning institutions. Developments in the open and distance learning arena give impetus to organisations Zimbabwe Open University (ZOU) included, for accelerated implementation of quality assurance management system. World Bank (2009:12) states that, ' at the global level, the International Network for Quality Assurance Agencies in Higher Education (INQAAHE) was established in 1991 to promote sharing of knowledge and experience in quality assurance." The African Council for Distance Education established the Continental Quality Assurance and Accreditation Agency for distance education in Africa in 2008. Rather belated to the SADC Protocol on Education agreement signed in 1997 in Blantyre, Malawi which inter-alia, aims for the ;

- Increasing quality access, improving quality and ensuring the relevance of education and training.

- Rationalising admission requirements to education and training institutions and accreditation of qualifications.

- Achieving comparability, equivalence and standardisation of education and training systems. (http://www.sadc.int/english/protocol/p-education-and-training.html).

It becomes clear that continental and regional efforts in putting in place quality assurance management systems will eventually be synchronised in cascading fashion from the continental level to regional, national and institutional level. In Zimbabwe, at the national level, the first coordinating body was put in place in 2006 and named The National Council for Higher Education which was re-launched as The Zimbabwe Council for Higher Education (ZIMCHE) in 2009 to monitor the quality of education in all higher education institutions in Zimbabwe be they public or private. At institutional level ZOU put in place the Quality Assurance Unit in 2007. 


\subsection{Why ZOU Needs an Effective Quality Assurance System}

There are three compelling reasons for ZOU to have a strong QA system namely professionalism, regulation and market forces. Globally demand for higher education has soared. World Bank (2009:9) notes that, "projections gave 120million students world-wide by 2020.' By 2004 the enrolment was already 132million. Bhebe (2011) declares that growth in student numbers has by and large been a response to the demand for university education in our communities. In an environment of great demand, institutions are likely to respond by increasing their enrolments but there is definitely need for a good quality assurance system for a university like ZOU to demonstrate its professionalism so as to remain relevant. World Bank (2009) concurs with the above assertion by observing that there is need for a robust system to ensure that programmes offered are in response to the socioeconomic needs of the society they serve. In that regard, ZOU established a Quality Assurance Unit (QAU) so as assure its stakeholders that it is not only responding to demand but indeed to deliver a quality service.

Bhebe (2011:1) laments that," due to competing obligations and priorities on the part of government, the resources available have been diminishing. The scenario is not peculiar to Midlands State University but indeed to all state universities in Zimbabwe. Actually the World Bank (2009) points out that the situation prevails in African universities. AAU/World Bank (1997) concurs by stating that, "there are increasing enrolments, yet the funding is declining in real terms.' In view of the rapid growth of tertiary enrolment without a matching increase in funding, quality assurance systems diminish the perception that some programmes may be used as fundraising initiatives by universities.

The second driver for ZOU's quality assurance effort is the need to fulfill the demand for transparency and accountability thereby fulfilling the regulatory dictates for higher education. World Bank (2009:10) observes that, 'an effective quality assurance system promotes transparency and accountability as institutions are required to open up to external scrutiny by peers, professional associations and national Quality Assurance (QA) agencies where they exist." An effective QA system creates the platform for harmonisation of qualifications and awards for regional collaboration. At present there is no harmonisation of qualifications and awards at the international and regional levels but there are strong indications that this will be achieved in the long run because of the developments of QA structures taking place. World Bank (2009:12) states that, "at the global level, the International Network for Quality Assurance Agencies in Higher Education (INQAAHE) was established in 1991 to promote sharing of knowledge and experience in quality assurance." At continental level we have the Continental Quality Assurance and Accreditation Agency formed in 2008. Whilst there is no known QA body at (SADC) regional level, it is necessary in view of the SADC protocol on education of 1997. At national level ZIMCHE was formed in 2009 to monitor the quality of education in all higher education institutions both private and public (Kurasha and Gwarinda 2011). It is ZOU's hope that through QAU there will be harmonisation of qualifications and awards through collaboration with the above stated agencies.

Market Forces: Increasing competition and shorter knowledge cycles require continuous improvement (World Bank 2009). While ZOU is the university mandated to offer distance higher education, most public universities in Zimbabwe have created variations of ODL known as block release, parallel programmes or visiting schools (Kurasha and Gwarinda 2011). These are a complete devolution from the usual part time programmes offered by conventional universities. This development influenced ZOU to seek continuous improvement of quality so as to beat rivals and maintain its first-mover advantage in Open Distance Learning (ODL) in Zimbabwe. Such competition is not confined to local universities as observed by World Bank (2009) that, stiff competition in the developed world has forced institutions to seek new markets in the developing countries. Universities from Malaysia, Russsia and the United Kingdom advertise and recruit students from the local market. In the face of such competition, an effective QA system serves to continuously monitor new knowledge creation by encouraging the institution to regularly update curricula, teaching methods and learning approaches.

Having seen the desirability of the QAU, ZOU put in place the unit with the main aim being to ensure institutional accountability and quality improvement. These major goals were to be operationalised through key performance areas espoused by Gwarinda and Kurasha (2011:5) as;

- Planning and designing quality management systems in line with the policies and best practices that meet the vision, mission and core values of the university; 
- Development, promotion and management of quality within the institution;

- Monitoring the implementation of quality improvement plans;

- Reviewing reports on the internal and external analyses and evaluations of institutional performance; and

- Providing research information to support the self-auditing, policy formulation, decision-making, planning and development of the institution to give ZOU a strategic advantage in higher education.

This paper seeks to explore the impact of the Quality Assurance Unit this far within the ZOU.

\section{Statement of the Problem}

Newton (2013) notes that the impact of quality assurance is an area that is under-researched. In the same vein, ZOU put in place the Quality Assurance Unit in 2007. The unit became fully fledged in 2010. However, the impact of the quality assurance Unit has not been studied and documented.

\section{Purpose of the Study}

The purpose of this study is to contribute to the new body of knowledge by exploring the impact of the Quality Assurance Unit as far as promoting accountability and facilitating quality improvement is concerned.

\section{OBJECTIVES OF THE STUdY}

To establish the impact of the QA system on the quality of teaching

To establish the impact of ZOU's QA system on the quality of learning.

To determine the impact of ZOU's QA system on the organisation and management issue of ZOU.

To discuss the academics' perceptions and behavior on the impact of the QA system in ZOU.

\section{RESEARCH QUESTIONS}

1. What are the major impacts of the QA system in ZOU on teaching?

2. To what extent has the learning function benefited from the QA system in ZOU?

3. Has the organization and management of ZOU benefited from the QA system being implemented?

4. What has been the major impact of quality assurance on the behavior and perceptions of academics in HEIs?

\section{REVIEW OF RELATED LITERATURE}

\subsection{Theoretical Framework}

Assessing the impact of the QAU in the institution is not linear. It is generally difficult to ascribe improvement to a QAU only since the university is usually carrying out several self improvement initiatives through policy refinements and unit improvements continuously. Grifoll, Leiber, Moldt, Rasmussen and Sorensen (2013:27) also note that "causal analyses of the corresponding sociological processes are missing---- presumably because such analyses are very laborious." The complexity arise from the multiplicity of variables involved.

This study adopts the Context, Input, Process and Product evaluation model, developed by the Phi Delta Kappa Committee on evaluation in 1971 (Smith 1980). Zhang, et al (2011:2) contend that the CIPP model is an improvement/accountability approach to evaluation, with the objective of determining the worth or merit of a programme. This model suited the objective of this research as it sought to determine the worth or merit of instituting the QAU in ZOU. The model is applicable at various stages of a programme, that is, during planning, implementation and or evaluation stage. In this case it is used as formative evaluation as the QAU needs continuous evaluation in order to improve its performance. The Context helps to identify the organisational needs in putting in place the QAU. Kurasha and Gwarinda (2011:2) observed that, "the increasing enrollment trend raised the quality assurance pressures on the institution (ZOU) especially when public accountability increased and student queries were also on the rise. To that end the QAU was instituted as a response to fulfill accountability concerns, address student queries, improve on programme offerings and provide the link between the institution and external quality assurance bodies (Kurasha and Gwarinda 2011). 
The Input relates to the response given to address the identified needs. In this case ZOU put in place the QAU which is dedicated to solving quality and accountability issues.

The process component focuses on the project process, procedures and the possibility of adjustments (Zhang et al 2011). In the context of ZOU the QAU set out to meet its objectives by putting in place a quality management system through policies, procedures and monitoring its effectiveness through self assessments and audits.

Product evaluation focuses on measuring, interpreting and judging the outcomes for their merit, worth and or significance (Zhang et al 2011).

\subsection{The Concept of Quality}

World Bank (2007:3) defines quality as, "meeting or conforming to generally accepted standards as defined by an institution, quality assurance bodies and appropriate academic and relevant professional bodies without due recognition of the customer." Gandhe (2009:3) contends that quality in education is a combination of,

- Exceptionally high standards

- Perfection and consistency

- Fitness for purpose

- Value for money and

- Transformation capabilities

Exceptionally high standards and value for money are notions held by the customer. A decision to commit oneself to a product or service is based on value for money by the customer. Implied in specification are standards and purpose. Two aspects defining quality seem apparent, measuring up to specification and meeting and even exceeding customer requirements (Greenwood \& Gaunt 1994; Bradley 1993; Herman 1993). Quality can be defined as the characteristics of a product or service that consistently satisfy specified standards set by experts and meeting or exceeding and stakeholder customer requirements.

\subsection{Quality Assurance in Higher Education}

Olusola (2011:3) defines quality assurance as, "the systematic monitoring and evaluation of the various aspects of a project, service or facility to ensure that standards of quality are met." Olubor and Ogonor (2008:4) define quality assurance as, 'a set of activities or procedures that an organization undertakes to ensure that standards are specified and reached consistently for a product or service." From the above citations, quality assurance can be defined as a process of building-in quality by carrying out a set of activities to ensure that set standards are met. In higher education it means that students enrolled should acquire the requisite competencies and display them at exit. These can be achieved by employing appropriate policies, structures, resources and procedures (Gwarinda \& Kurasha 2011).

\subsection{Measuring the Impact of Quality Assurance}

According to Kefalas et al (2003) a quality assurance system is applied to the course/programme/ curriculum, the staff, learning methods, technology, services and the organisation and managerial structure. Kis (2005) streamlines the impact of quality assurance mechanisms to three as the elements identified by Kefalas can be fused into the latter's list, that is, on teaching and learning, organisation and management issues and academics' perceptions on QA.

\subsection{Impact of QA on Teaching}

QA instruments examine the teaching aspect of universities. Assessment tools cover areas such as the curriculum, teaching methods, students' experiences, pedagogies, student assessment amongst other issues (ZIMCHE Programme Inputs Assessment Instrument (ACCR 3C) sections 1.1, 1.5 and 1.6 2011). While this is an external document, such have always been used to develop institutional checklists for programme accreditation and other improvement and compliance purposes. According to Silva et al (1997) external quality evaluation led to improvement in curriculum. QA should also have an impact on how the curriculum is executed. Brennan and Shah (2000) argue that the institution of QA systems have resulted in greater discourse on teaching, pedagogies and assessment of teaching 
such as the QA systems also concern themselves with the students so enrolled, their support and assessment as part of the teaching process. A case in point is the ZIMCHE Programme Inputs Assessment Instrument (ACCR 3C) sections 1.2, (Student recruitment, admission and selection), 1.3, (Staffing of programme), 1.4 (Staff complement) and 1.7, (Infrastructure and resources). QA processes such as staffing criteria, promotion criteria. Silva et al further reported the positive impact of QA systems in hiring and promotion of academic staff, higher standards for staff, more incentives to conduct and publish research and creative writing such as ZIMCHE Instutitonal Accreditation instrument ACCR 1B sections 4 and 5 and PRC 1 Section 5.

\subsection{Quality in Learning}

ZIMCHE PRC 1 a guide for institutional practice in learning benchmarks outlines the criteria for special facilities (Section 8), criteria for duration and weighting of programmes (Section 9) and student assessment (Section 10) amongst other issues. These have to be pursued through the effective application of QA to improve learning.

Nyenya and Rupande (2014) concluded that quality circles as a QA strategy, improved teaching and learning as students' feedback and continuous cooperative problem solving is a common feature. Students' feedback empowers them as they can determine what and where to study (Brennan and Shah 2000) how learn and who to teach them. QA systems help to clarify responsibility for improvement of teaching and learning (Dill 2000, Nyenya and Bukalia 2014).

It has to be noted that the above description shows the compliance and accountability imperatives in QA Harvey and Newton (2004). While the driving force may be compliance and accountability, the spirit is to improve on quality of learning (Harvey 1997). This research thus focuses more on the outcome as evidenced by the respondents' views on the outcome of implementing QA in ZOU.

\subsection{Impact of QA on the Organisation and Management Issues}

Since the introduction of the new QA dispensation in ZOU around 2011 to date the focus has been on continuous improvement through the implementation of a university quality management system. The system is based on the ISO 9001:2008 philosophy. It emphasises on the systems approach. Its impact should be examined on the whole system, organisation and management issues included. Stensaker (2003) contends that EQA systems are concerned with organisational requirements other than teaching and learning. Power (1994) notes that quality audits, as QA instruments have been viewed as administrative control over the work of academics. Kis (2005) concurs by stating that EQA affects the power distribution within institutions where emphasis on internal policies and procedures impinge on the disciplinary cultures, thereby striping academics of the previously wielded power entrenching centralisation (Askling 1997). Closely related to centralisation, Kogan et al (2000) concluded that EQA promoted bureaucracy.

QA promotes the effective use of committees in decision-making following set procedures. Decisionmaking is based on objective data. Kis (2005) notes that evaluations have made the decision-making process more open and quantifiable. It can be argued that QA leads to transparency.

\subsection{The Impact of Quality Assurance on Academics Behaviour and Perceptions of the QAU in HEIs}

Nyenya and Bukaliya (2014) established that audits as a QA tool helped academics to locate their jobs clearer in the achievement of university objectives. They also established that discussion during the audit opening and audit closing meetings helped academics to "establish the major problems and come up with solutions to improve operations." This view is shared by Dill (2000) who also discovered that audits as a QA process facilitated discussion, cooperation, and improvement of academics' teaching and learning processes.

Research is another area where QA mechanisms might have an impact on academics. For example, ZIMCHE PRC 1 Section 5.3 Criteria for Promotion spells out the research output required to achieve various status. Through awareness and constant monitoring of academics' research output QA can inspire academics to improve their status and that of the institution. Research can also be used to foster teamwork through collaborative studies. This view is also shared by Newton (2001) who asserts that QA mechanisms entrench teamwork. 
On the other hand, Baldwin (1997) suggests that academics view QA mechanisms as substantiating managerial prerogatives associated with accountability. Nyenya and Bukaliya (2014) also established the same when they concluded that the Quality Management System is laborious due to excessive need for documentation (Askling 1997 and Harvey 2002). They also established that academics view QA mechanisms as impinging on their professionalism. Similarly, Newton (2001) argues that the involvement of senior management in centralised decision making on issues concerning curriculum design and teaching standards and the need to ensure that the product meets both institutional and external monitoring requirements all lead to loss of academic autonomy.

\section{Methodology}

The qualitative inquiry is used to explore the impact of the quality assurance unit using ZOU as a case study. LeCompte and Schensul (1999) identify the natural setting as one of the characteristics of qualitative research. This inquiry will gather data from participants at their work places with the researcher as a key instrument in data collection whereby he conducts interviews Hatch (2002). The inquiry focuses on participants' perspectives and their subjective views (LeCompte and Schensul 1999) of the impact of the quality assurance unit at ZOU. In addition to interviews, document analysis will be conducted to gather evidence on the activities of the quality assurance unit. These include media articles, and internal reports.

\section{Population}

According to Castillo (2009), a research population is a group of people having similar characteristics, which are of interest to a researcher. This research seeks to identify the impact of the quality assurance unit in ZOU; therefore, the population for the study is the ZOU staff, students and major stakeholders. The population have their views of the impact of the quality assurance unit which can act as markers of success or otherwise. ZOU has a full time staff compliment of about 850, a part time staff compliment of about 1100 and a student body of about 11000. Due to time and financial constraints information cannot be elicited from the entire population, therefore a sample will be used.

\section{SAMPLing}

The manager quality assurance, 4 of the 10 regional directors, 4 of the 10 regional quality assurance coordinators, 4 of the 10 student representative council members, 12 of the 200 full time academics in 6 Faculties of ZOU will be interviewed. Their views cut across the ZOU population. The experiences of the quality assurance director will also be explored as he is also a core-author.

\section{Data Analysis}

Data will be qualitatively analysed using the various themes identified in literature review.

\section{FindingS AND DISCUSSION}

\subsection{What have been the Major impacts of the QA System in ZOU on Teaching?}

Document analysis was conducted on Regional Office's staffing records. All of the 70 active fulltime and part time academics engaged in Mashonaland East Region have at least a Master's degree. This is line with the quality assurance requirements that academic staff be at least Masters' degree holders. These findings are in line with ZIMCHE Programme Inputs Assessment Instrument (ACCR 3C) sections 1.3, (Staffing of programme), showing that QA ensures compliance with regulatory requirements.

In response to questions on the impact of QA on teaching one Regional Programme Coordinator noted that better teaching methods are evident as tutors are aware of the fact the RPC will be observing their teaching habits. Another respondent noted that through the ISO 9000 awareness workshop, tutors had the opportunity to discuss their overall conduct including effective pedagogies. Yet another respondent pointed out that assessment methods have greatly improved, with constructive comments observed on students' assignments. The use of students' feedback is an effective tool for change. This calls for closer consideration of one's use conduct during tutorials. The findings concur with Brennan and Shah (2000) who argue that the institution of QA systems have resulted in greater discourse on teaching, pedagogies and assessment of teaching such as the QA systems also concern themselves with the students so enrolled, their support and assessment as part of the teaching process. 
The Regional Director responded that the QA had made impact on teaching by ensuring that the facilities for the venue were always according to specifications, in the best possible environment with attendant facilities up to standard. The findings suggest that the requirements of the ZIMCHE (ACCR 3C) 1.7 (Infrastructure and resources) are adhered to as a result of the awareness brought about by QA. These efforts not only facilitate learning but act as marketing points. ISO 9001 awareness programme ushered in a paradigm shift for lecturers by bringing the student centred approach to service delivery.

The Director QA also had his own input by noting that the lifting of the suspension Bachelor of Science in Counseling in June 2013 was a collective QA effort of the university. This was achieved with QA techniques to identify root causes and the needed corrective action and interfacing with ZIMCHE. Similar efforts were made by the QA to facilitate the lifting of the suspension Master of Science in Counseling by December 2013. Collective QA practice played a pivotal role in the publication of examination results, which took 3 months in 2011, improved to 4 weeks from 2013 to 2014 and 3 weeks in 2015.

\subsection{To what Extent has the Learning Function Benefited from the QA System in ZOU?}

One academic pointed out that one of the key issues that resulted in the non-recognition was the assessment of the students, which had weak supervision of students on teaching practice. The involvement of QA made an impact, which resulted in the recognition for employment of ZOU graduates of the Diploma in Education Primary in May 2014. Through the documented procedure on handling defective product, QA managed the situation and subsequently emphasising on the fulfillment of the ZIMCHE PRC 1 Section 10 procedure for student assessment.

One academic noted that the institution of anti-plagiarism software (Turn it in) had improved the quality of research by both the students and academics where QA took the responsibility for improvement as purported by Nyenya and Bukaliya (2014). Document analysis revealed the various feedback mechanisms in place which give impetus to improved teaching and learning. The finding concurs with Brennan and Shah (2000) view that students' feedback empowers them to determine what and where to study, how to learn and who to teach them. These include student satisfaction surveys, modules and tutor evaluation instruments. Evidence on the use of the instruments was available. Yet another academic noted that at Regional level there was a documented complaints handling procedure. The procedure aided in improving the quality of student experiences. Employer satisfaction surveys aid in designing market driven programmes and learning so as to satisfy the market.

\subsection{Have Organisation and Management Issues in ZOU Benefited from the QA System Implemented?}

ZOU Senate records revealed that Senate meetings that took 2-3 days in 2011, now take half a day since 2012. Such time savings lead to significant time set aside for other management issues. The documents also revealed that customer satisfaction improved over the period from $30.4 \%$ in 2011 to 47.4\% in 2012 and $77.3 \%$ in 2013. These improvements have come on the heels of objective; information based decision-making (Kis 2005). University local ranking improved significantly from ten in 2011 to five in February 2015. Astute quality assurance practices have earned the institution several accolades which include being the first University in Zimbabwe to be awarded the International Star for Leadership in Quality (London, 2012) and the Century Quality Era Award (Geneva, 2014). The first University in Zimbabwe to pass the ISO 9001 stage 1 audit.

\subsection{What have been the Major Impacts of Quality Assurance on Academics Behaviour and Perceptions of the QAU in HEIs?}

With regards the perceived impact of QA systems on academics, one responded that systems had helped in identifying best practices which can be pursued. These are outlined during internal quality audits and routine quality awareness and monitoring exercises.

Document analysis indicated that 242 research papers were published in 2013 institution wide and these rose to 282 in 2014 courtesy of setting SMART objectives the for all the processes by the QA unit. The QAU conscientised faculty on the ZIMCHE PRC 1 Section 5.3 Criteria for Promotion that spells out the research output required to achieve various status thereby giving impetus to increased research output. 
One academic pointed out that quality assurance heavily relies on objective evidence of the fulfillment of procedures a view put forward by Baldwin (1997) who propounded that academics view QA mechanisms as substantiating managerial prerogatives associated with accountability. Academics decried losing sense of professionalism embedded in expertise in an area as also established by Askling (1997) and Harvey (2002).

\section{CONCLUSION}

This study has established that the Quality Assurance Unit in ZOU has positively impacted on;

- Teaching through adherence to ZIMCHE staffing and facilities specifications

- Through quality audits and ISO 9001 awareness programmes initiated discussion on teaching methods and assessment methods

- Through quality assurance techniques the unit facilitated with lifting of the suspension of two of ZOU's programmes while time to publish results reduced from 3 months in 2011 to 3 weeks in 2015

- Improvements on the Diploma in Education Primary led to its recognition for employment from May 2014

- The use of feedback mechanisms have resulted in improved teaching and learning

- Senate meetings that took 2-3 days in 2011, now take half a day since 2012.

- Customer satisfaction improved over the period from 30.4\% in 2011 to $77.3 \%$ in 2013

- University ranking improved from 11 in 2011 to 5 in 2014

- Three international quality awards have been received from 2012 to 2015

- Academics research output has increased from 242 in 2013 to 282 in 2014.

\section{RECOMMENDATIONS}

In view of the several achievements made by the Quality Assurance Unit in ZOU it is strongly recommended that the unit continues to strive for excellence. Continued managerial support through resource allocation to address non-conformities is vital.

\section{REFERENCES}

AAU/World Bank (1997). Revitalising Universities In Africa. Strategy \& Guidelines. Washington D. C. Association of African Universities \& The World Bank.

Askling, B. (1997). Quality Monitoring as an Institutional Enterprise. Quality in Higher Education, 3 (1), pp 17-26.

Baldwin, G. (1997). Quality Assurance in Australian Higher Education: The Case of Monash University. Quality in Higher Education, 3 (1), pp 51-61.

Brennan, J. and Shah, T. (2000). Quality Assessment and Institutional Change: Experiences from 14 Countries, Higher Education, 40

Dill, D. D. (2000). Designing Academic Audit: Lessons Learned in Europe and Asia, Quality in Higher Education 6 (3).

Gandhe, S. K. (2009). Quality Assurance in Open and Distance Learning in India. Symbiosis Centre for Distance Learning, India.

Grifoll, J., Leiber, T., Moldt, C., Salado-Rasmussen, J. and Sorenson, M. (2013). Measuring the Impact of External Quality Assurance- Or: Preparing External Quality Assurance for a Greater Impact on Higher Education, in How Does Quality Assurance Make a Difference (Ed.) EUA Case Studies: Brussels.

Harvey, L. (1997). Obstacles to Transforming Higher Education, Keynote Presentation at the 'Studying Obstacles Conference Organised by LSVB, Nijmegen, The Netherlands, 20-21 March.

Harvey, L., and Newton, J. (2004). Transforming Quality. Quality in Higher Education, 10 (2), pp 149-165. 
Kis, V. (2005). Quality Assurance in Tertiary Education: Current Practices in OECD Countries and Literature Review on Potential Effects. Tertiary Review.

Kogan, M., Bauer, M., Bleilie, I. and Henkel, M. (2000). Transforming Higher Education: A Comparative Study. London: Jessica Kingsley.

Kurasha,P. and Gwarinda, T.C. (2011). Financing A Sustainable Quality Assurance Model For National Development Through Open And Distance Learning In Higher Education: The Zimbabwean Experience. The Zimbabwe International Journal of Open \& Distance Learning Vol 1 No.1 2011.

LeCompte,M.D. and Schensul, J.J.(1999) Designing and Conducting Ethnographic Research.(Ethnographer's Toolkit, Vol.1) Walnut Creek, CA: AltraMira

Newton, J. (2001). Views From Below: Academics Coping With Quality, Keynote Presentation at the Sixth QHE Seminar in Association With EAIR and SRHE, $26^{\text {th }}$ May 2001, Birmingham, United Kingdom.

Newton, J. (2013). Is Quality Assurance Leading to Enhancement? In How Does Quality Assurance Make a Difference (Ed.) EUA Case Studies: Brussels.

Nyenya, T. and Bukaliya, R. (2014). Academic Staff Perceptions of the Impact of Internal Quality Audits: The Case of Zimbabwe Open University. International Journal of Innovative Research and Development, 3(6) pp. 533-538.

Nyenya, T. and Rupande, G. (2014). Quality Circle in Open and Distance Learning Institutions; Opportunities and Challenges: A Case of the Zimbabwe Open University. International Journal of Innovative Research and Development, 3(6) pp. 539-546.

Olubor, R. O. and Ogonor, B. O. (2008). Quality Assurance in Open and Distance Learning in National Open University of Nigeria: Concepts, Challenges, Prospects and Recommendations. Paper Presented at the ACDE Conference and General Assembly, Eko Hotel, Lagos $8^{\text {th }}-11^{\text {th }}$ July 2008.

Power, M. (1994). The Audit Explosion. London: Demos.

Silva, M., Reich, R., and Gallegos, G. (1997). Effects of External Quality Evaluation in Chile: A Preliminary Study, Quality in Higher Education, 3(1).

Smith, K. M. (1980). An Analysis of the Practice of Educational Programme in Terms of the CIPP Model (PhD Thesis). Loyola University of Chicago.

Stensaker, B. (2003). Trance, Transparency, and Transformation: The Impact of External Quality Monitoring on Higher Education, Quality in higher Education, 9 (2), pp 151-159.

World Bank (2009) Higher Education Quality Assurance In Sub-Saharan Africa. Washington D.C. World Bank.

Zhang, G., Zeller, N., Griffith,R., Metcalf, D., Williams, J., Shea, C. and Misulis, K. (2011). Using the Context, Input, Process, and Product Evaluation Model (CIPP) as a Comprehensive Framework to Guide the Planning, Implementation, and Assessment of Service-Learning Programmes. Journal of Higher Eduucation Outreach and Engagement, Vol. 15, (4) pp 57.

Zimbabwe Council for Higher Education (undated) Criteria for Accreditation of Open and Distance Learning Programmes, Harare

Zimbabwe Council for Higher Education (undated) Programme Inputs Assessment Instrument (ACCR 3C, PRC 1), Harare

http://www.sadc.int/english/protocol/p-education-and-training (12-07-12)

\section{AUTHOR's BIOGRAPHY}

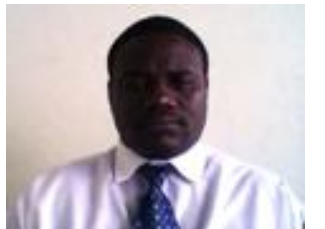

MR. TRUST NYENYA, is the Regional Quality Assurance Coordinator for ZOU's Mashonaland East Region. He is an educationist and academic with vast experience spanning over twenty years in all sectors of the education from primary education to higher education. He holds a Certificate in Education (UZ), Bachelor of Education in Educational Administration, Planning and Policy Studies (ZOU) and Master of Business Administration (ZOU). He has published research articles in education and quality assurance. He is a DPhil student working on a thesis in quality assurance. His research interest is in quality assurance and educational assessment and human resources. 